Applied Physiology, Nutrition, and Metabolism

Canadian Science Publishing Physiologie appliquée, nutrition et métabolisme

\title{
Human skeletal muscle contains no detectable guanidinoacetic acid
}

\begin{tabular}{|c|c|}
\hline Journal: & Applied Physiology, Nutrition, and Metabolism \\
\hline Manuscript ID & apnm-2017-0873.R1 \\
\hline Manuscript Type: & Brief communication \\
\hline Date Submitted by the Author: & 26-Jan-2018 \\
\hline Complete List of Authors: & 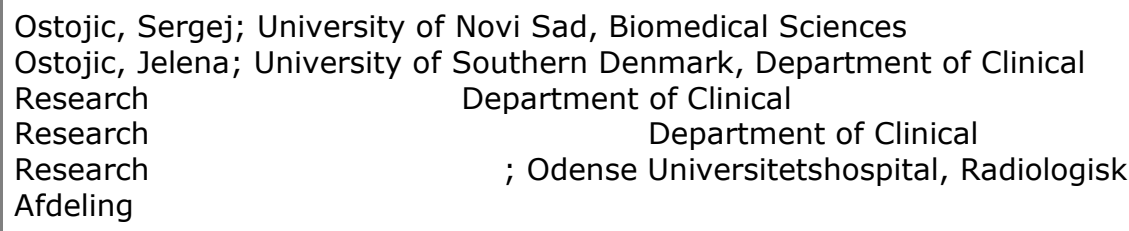 \\
\hline Keyword: & $\begin{array}{l}\text { guanidinoacetic acid, magnetic resonance spectroscopy, vastus medialis } \\
\text { muscle }\end{array}$ \\
\hline $\begin{array}{r}\text { Is the invited manuscript for } \\
\text { consideration in a Special } \\
\text { Issue? : }\end{array}$ & N/A \\
\hline
\end{tabular}

SCHOLARONE ${ }^{\text {tw }}$

Manuscripts 


\title{
CASE REPORT
}

\section{Human skeletal muscle contains no detectable guanidinoacetic acid}

\author{
Sergej M. Ostojic ${ }^{1,2}$, Jelena Ostojic ${ }^{3}$ \\ ${ }^{1}$ Faculty of Sport and Physical Education, University of Novi Sad, Novi Sad, Serbia \\ ${ }^{2}$ University of Belgrade School of Medicine, Belgrade, Serbia \\ ${ }^{3}$ Faculty of Health Sciences, University of Southern Denmark, Odense, Denmark
}

\author{
* Correspondence \\ Professor Sergej M. Ostojic, MD, PhD \\ ORCID ID: http://orcid.org/0000-0002-7270-2541 \\ Applied Bioenergetics Lab, Faculty of Sport and Physical Education \\ University of Novi Sad, Lovcenska 16, Novi Sad 21000, Serbia \\ Phone: (++381)-21-450-188 | Fax: (++381)-21-450-199 \\ E-mail: sergej.ostojic@.chess.edu.rs
}

Running head

Word count

Number of references

Number of figures
Guanidinoacetic acid in the human muscle

1161

7

1 


\begin{abstract}
We analyzed data from previously completed trials to determine the effects of supplemental guanidinoacetic acid (GAA) on markers of muscle bioenergetics in healthy men using $1.5 \mathrm{~T}$ magnetic resonance spectroscopy. No detectable GAA $(<0.1 \mu \mathrm{M})$ was found in the vastus medialis muscle at baseline nor at follow-up. This implies deficient GAA availability in the human skeletal muscle, suggesting absent or negligible potential for creatine synthesis from GAA inside this tissue, even after GAA loading.
\end{abstract}

Keywords: guanidinoacetic acid; magnetic resonance spectroscopy; vastus medialis 
Creatine synthesis in tissues with high-energy demands remains somewhat puzzling, concerning the availability of guanidinoacetic acid (GAA), a direct natural precursor of creatine and an intermediate in cellular bioenergetics. The liver, kidney and pancreas are recognized as the main organs of creatine synthesis, with GAA concentrations varied in the range of 0.5 and $1 \mathrm{mM}$ across specific tissues (Wyss \& Kaddurah-Daouk 2000). Creatine-synthesizing forerunner is also available in the brain, with GAA detectable in the grey and white matter of healthy humans at levels of $\sim 0.2 \mathrm{mM}$ (Ostojic \& Ostojic 2018). Another energy-consuming organ, the skeletal muscle, has also been suggested as a possible site of GAA-to-creatine synthesis (Daly 1985). However, specific studies are rather rare, with no evidence available concerning the GAA availability in the human skeletal muscle.

In this report, we conducted a secondary analysis of previously completed trials (Ostojic et al. 2016a; Ostojic et $a l$. 2016b) aimed to determine the effects of GAA loading on markers of muscle bioenergetics in healthy men using $1.5 \mathrm{~T}$ proton magnetic resonance spectroscopy (MRS) studies. For this communication, MRS spectra from 10 healthy men (age $23.5 \pm 3.1$ years) were additionally analyzed for GAA concentrations in the vastus medialis muscle using TARQUIN 4.3.10 software package at the baseline and following GAA supplementation. We evaluated quantitatively 30 spectra for presence of GAA peak at $3.8 \mathrm{ppm}$. The TARQUIN algorithm performs a fully automated fit to the data using a predefined basis set, with a detection limit for GAA in vivo was $\sim 0.1 \mu \mathrm{M}$ (Ostojic \& Ostojic 2018). A detailed information of the methods used, including participants details, ethical standards, and GAA dosages administered, has been described previously (Ostojic et al. 2016a; Ostojic et al. 2016b). In short, volunteers were supplemented with up to 4.8 grams of GAA daily for 8 weeks, with metabolic profiles monitored at baseline, 4-wk and 8-wk intervals.

No detectable GAA was found in the vastus medialis muscle of healthy men at baseline nor at follow-up. An algorithm employed revealed average GAA levels $<0.1 \mu \mathrm{M}$ at the baseline, with no relevant peaks were noted in MR spectra at $3.8 \mathrm{ppm}$ corresponding to GAA in any participant (Figure 1). Exogenous GAA administration demonstrated no effect on muscle GAA levels, with GAA remained below detection limit in our cohort of healthy men.

- Figure 1 about here -

The present analysis implies deficient GAA availability in the human skeletal muscle, suggesting an absent or negligible potential for creatine synthesis from GAA inside this tissue, even after GAA loading. GAA drives creatine synthesis, with muscle creatine improved for $\sim 8.4 \%$ after oral GAA intake (Ostojic et al. 2016b), yet it appears that organs other than the skeletal muscle play a role in this process. A limited GAA transport from the circulation to the muscle cell due to transporter specificity might account for poor GAA availability (JoncquelChevalier Curt et al. 2015), rather than a shortage of guanidinoacetate $N$-methyltransferase (GAMT), an enzyme that catalyzes the methylation of GAA to creatine. The specific activity of GAMT in the muscle appears to be low (Wyss \& Kaddurah-Daouk 2000) yet enough to synthesize all creatine needed in this tissue (Daly 1985). Therefore, a low GAA bioavailability might be due to the possible competition between circulating GAA and creatine for mutual membrane transporter (SLC6A8) (Tachikawa et al. 2009), with creatine as a high-affinity substrate fends off GAA 
from the muscle cell. Muscle GAA levels also appeared to be immune to GAA supplementation, with creatine has been rather synthesized elsewhere and delivered to the muscle afterwards. Further well-powered confirmatory trials are highly warranted, but also studies with labeled GAA to characterize its kinetics in physiological conditions and during interventional trials. In addition, the use of more powerful imaging systems in future studies (e.g. $3.0 \mathrm{~T}$ proton MRS) might provide a sufficient resolution to determine GAA levels in the skeletal muscle (also brain), specifically for mild-to-moderate changes in tissue GAA concentrations after dietary interventions. Finally, supplemental GAA must be carefuly scrutinized in the subsequent bioavailability trials due to its secondary effects, including methyl group consumption and homocysteine overproduction (Ostojic et al. 2016b)

\section{Conflict of Interest}

The authors report no conflicts of interest associated with this manuscript.

\section{Funding information}

Study was supported by the Serbian Ministry of Education, Science and Technological Development (175037), the Provincial Secretariat for Higher Education and Scientific Research (114-451-710), the Faculty of Sport and Physical Education, and the Center for Health, Exercise and Sport Sciences.

\section{References}

Daly, M.M. 1985. Guanidinoacetate methyltransferase activity in tissues and cultured cells. Arch. Biochem. Biophys. 236: 576-584. PMID: 3970526

Joncquel-Chevalier Curt, M., Voicu, P.M., Fontaine, M., Dessein, A.F., Porchet, N., Mention-Mulliez, K., et al. 2015. Creatine biosynthesis and transport in health and disease. Biochimie. 119: 146-165. DOI: 10.1016/j.biochi.2015.10.022

Ostojic, S.M., and Ostojic, J. 2018. Dietary guanidinoacetic acid does not accumulate in the brain of healthy men. Eur. J. Nutr. (in press) doi: 10.1007/s00394-017-1600-2

Ostojic, S.M., Drid, P., and Ostojic J. 2016a. Guanidinoacetic acid increases skeletal muscle creatine stores in healthy men. Nutrition. 32: 723-724. DOI: 10.1016/j.nut.2015.11.006

Ostojic, S.M., Ostojic, J., Drid, P., and Vranes, M. 2016b. Guanidinoacetic acid versus creatine for improved brain and muscle creatine levels: a superiority pilot trial in healthy men. Appl. Physiol. Nutr. Metab. 41: 10051007. DOI: 10.1139/apnm-2016-0178

Tachikawa, M., Kasai, Y., Yokoyama, R., Fujinawa, J., Ganapathy, V., Terasaki, T., et al. 2009. The blood-brain barrier transport and cerebral distribution of guanidinoacetate in rats: involvement of creatine and taurine transporters. J. Neurochem. 111: 499-509. DOI 0.1111/j.1471-4159.2009.06332.x

Wyss, M., and Kaddurah-Daouk, R. 2000. Creatine and creatinine metabolism. Physiol Rev. 80: 1107-1213. DOI: 10.1152/physrev.2000.80.3.1107 


\section{FIGURE CAPTION}

Fig 1. An example of magnetic resonance spectra for vastus medialis muscle metabolites illustrates no detectable peak for guanidinoacetic acid (GAA) at 3.8 ppm (red arrow) at baseline (Panel A), also at 4-week (Panel B), and 8week follow-up (Panel C) in a 23-year old young men. Cho - choline, Cr- creatine, Lip - intramyocellular lipids. 

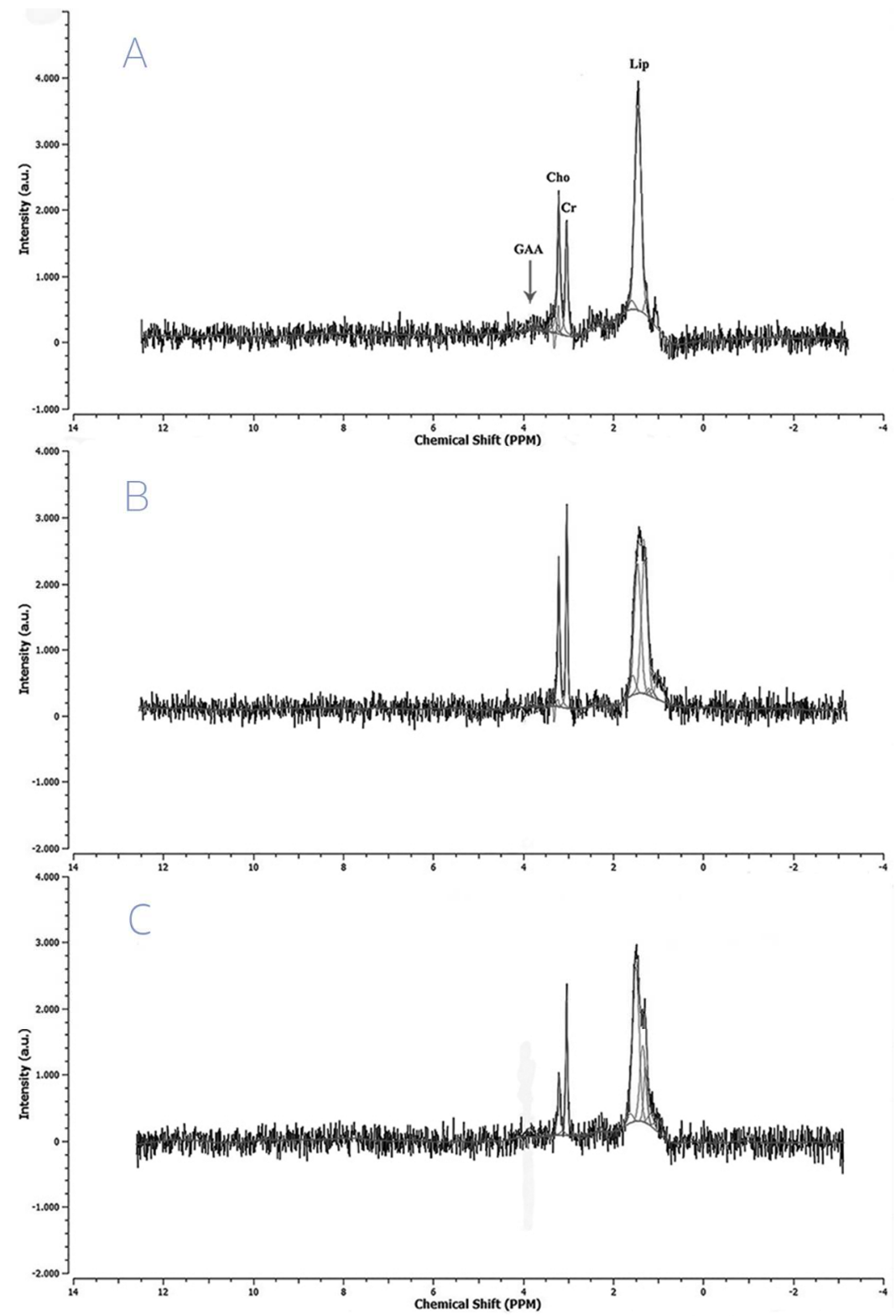